\title{
8
}
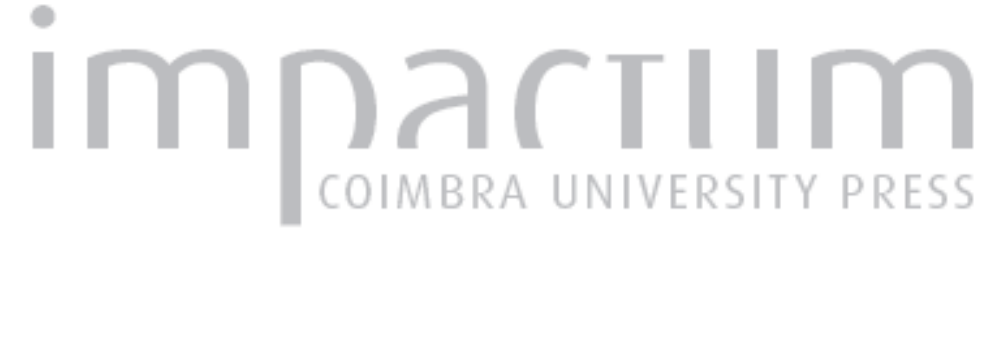

\section{Variedade de gêneros e teatralidade nos dramas de Sêneca}

Autor(es): $\quad$ Lohner, José Eduardo dos Santos

Publicado por: Sociedade Brasileira de Estudos Clássicos

URL persistente:

URI:http://hdl.handle.net/10316.2/35799

DOI:

DOI:http://dx.doi.org/10.14195/2176-6436_24_6

Accessed : $\quad$ 26-Apr-2023 10:58:58

A navegação consulta e descarregamento dos títulos inseridos nas Bibliotecas Digitais UC Digitalis, UC Pombalina e UC Impactum, pressupõem a aceitação plena e sem reservas dos Termos e Condições de Uso destas Bibliotecas Digitais, disponíveis em https://digitalis.uc.pt/pt-pt/termos.

Conforme exposto nos referidos Termos e Condições de Uso, o descarregamento de títulos de acesso restrito requer uma licença válida de autorização devendo o utilizador aceder ao(s) documento(s) a partir de um endereço de IP da instituição detentora da supramencionada licença.

Ao utilizador é apenas permitido o descarregamento para uso pessoal, pelo que o emprego do(s) título(s) descarregado(s) para outro fim, designadamente comercial, carece de autorização do respetivo autor ou editor da obra.

Na medida em que todas as obras da UC Digitalis se encontram protegidas pelo Código do Direito de Autor e Direitos Conexos e demais legislação aplicável, toda a cópia, parcial ou total, deste documento, nos casos em que é legalmente admitida, deverá conter ou fazer-se acompanhar por este aviso.

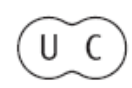




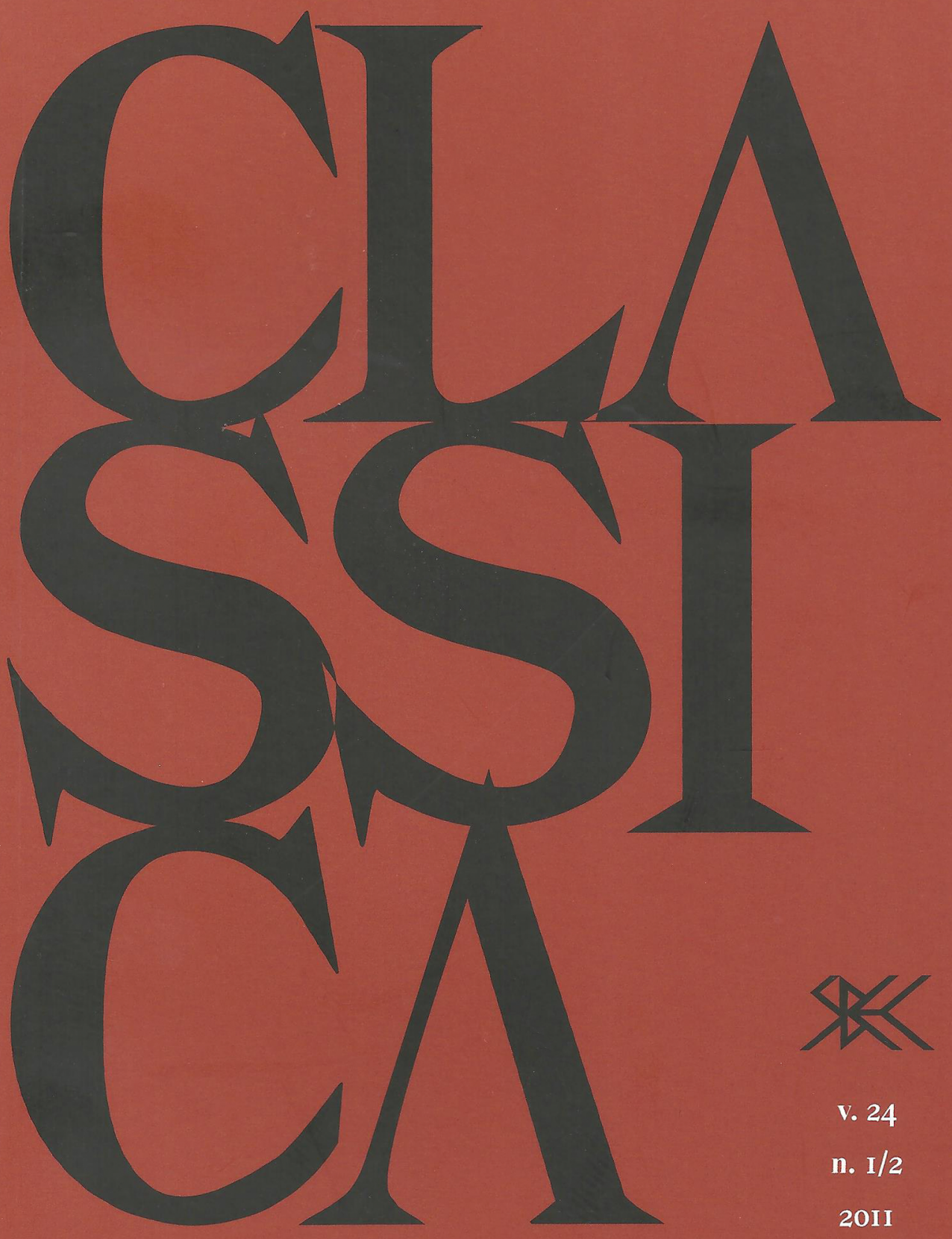




\title{
Variedade de gêneros e teatralidade nos dramas de Sêneca
}

\author{
José Eduardo dos SAntos LoHner \\ Universidade de São Paulo \\ Brasil
}

Resumo. A poesia dramática de Sêneca, como, em geral, a literatura da época imperial, é marcada pela influência estética do período helenístico. Entre outros aspectos, a mescla de gêneros discursivos, praticada por poetas alexandrinos, é em boa medida observável nos dramas senequianos, onde, aliás, há constantes referências a modelos não dramáticos, especialmente a lírica de Horácio e a épica de Virgílio e Ovídio, além do emprego de elementos formais do discurso declamatório. Considerando a questão longamente debatida pela crítica sobre o tipo de performance que o dramaturgo latino teria concebido para seus dramas, sugere-se então que a variação de formas discursivas, bem como o uso de modelos não dramáticos, seja um fator que interfere na teatralidade dessas peças. O resultado disso é um texto em que aparecem algumas cenas com conteúdo e características adequados à encenação no palco, ao lado de outras, de pouco efeito cênico e visual, nas quais se destaca antes o efeito auditivo do texto recitado e sua força descritiva operando na imaginação do ouvinte.

PalaVRas-chave. Tragédia latina; Sêneca; performance; variedade de gêneros.

A questão sobre a adequação das peças de Sêneca para a cena teatral vem sendo discutida desde o início do século XIX. A opinião de que essas peças não foram escritas para encenação em grandes teatros, mas para serem apenas declamadas no âmbito das escolas de oratória ou para leitura ou recitação diante de um público restrito foi formulada inicialmente por August Schlegel (1809) e defendida depois por Gaston Boissier (1861) e Friedrich Leo (1878). ${ }^{1}$ Os argumentos utilizados para fundamentar essa posição

E-mail: jelohner@usp.br

${ }^{1}$ A.W. von Schlegel, Über dramatische Kunst und Literatur. Vorlesungen, Heidelberg, Mohr \& Zimmer, 1809-11; G. BoIssier, Les tragédies de Sénèque ont-elles été représentées? Paris, 1861; F. Leo, De Senecae tragoediae observationes criticae, Berlin, 1878, cuja condenação do retoricismo da linguagem trágica de Sêneca foi sintetizada na frase istae uero non sunt tragoediae sed declamationes ad tragoediae amussim compositae, "na verdade, elas não são tragédias, mas discursos declamatórios compostos sob o molde de tragédias”. Ver J.G. Fitch, 'Playing Seneca?', in G.W.M. Harrison (ed.), Seneca in performance, London, The Classical Press of Wales, 1-12, 2000, p. 1. 
crítica basearam-se nos seguintes aspectos: 1) o estilo oratório, considerado artificial devido a uma ornamentação tida como excessiva e à frequência de falas de longa extensão; 2) a prática de ações sangrentas em cena; 3) a frouxa relação, incoerência ou contradição entre as cenas; 4) a larga prevalência da narração sobre a ação; 5) a quase ausência do coro nas seções dialogadas e seu distanciamento em relação aos eventos centrais da ação.

Ao longo do século XX, a questão manteve-se em debate, destacando-se dois estudos em que foram defendidas posições antagônicas²: o de Léon Herrmann, Le Théâtre de Sénèque, de 1924, favorável à concepção teatral dos dramas senequianos, e o de Otto Zwierlein, Die Rezitationsdramen Senecas, de 1966, que propôs a existência, desde o início da época helenística, de uma tradição de textos dramáticos concebidos apenas para leitura, tradição em que poderia ser inserida a obra de Sêneca. ${ }^{3}$ Apesar de atualmente a tese do drama para leitura ser aceita pela maior parte da crítica, persiste ainda certa polêmica, de modo que, de tempos em tempos, surgem trabalhos em que se defende o caráter teatral das tragédias de Sêneca, alguns, inclusive, fundamentados em experiências de encenação de uma ou outra das peças. ${ }^{4}$ Ao lado disso, formula-se também uma hipótese intermediária, expressa, por exemplo, por John Fitch, que

${ }^{2}$ Ver B. WALKer, Review of Zwierlein Rezitationsdramen Senecas. CPh 65, 183-7, 1969 , p. 184: The most systematic treatment of the question has been Herrmann's Le Theatre de senequi (Paris, 1924), and his conclusion is directly and emphatically opposed to that of Z. This gives Z. a formidable antagonist (whose points he sometimes fails to counter). ${ }^{3}$ Otto Zwierlein, Die Rezitationsdramen Senecas, Meisenheim am Glan, 1966, p. 14149, defende que a "tragédia para leitura" (Lesedrama) é um gênero que teve origem na época helenística: Wie die Mimen des Theokrit und des Herondas nicht für eine szenische Aufführung gedichtet sind, so gab es auch Tragödien, die sich nur an Leser (oder Hörer) wendeten: Die hellenistische Zeit kannte das Lesedrama. (...) Wie nahezu alle literarischen Gattungen Roms wurzelt auch das lateinische Lesedrama auf griechischem Boden (p. 149) ["Assim como os mimos de Teócrito e Herondas não são para uma performance cênica, assim também eram as tragédias, que eram dirigidas apenas a leitores (ou ouvintes): A época helenística conheceu o drama para leitura" (...) "Tal como praticamente todos os gêneros literários de Roma, o drama latino para leitura também está enraizado em solo grego"]. B. Walker (Review of...) contestou em parte os argumentos de Zwierlein. Segundo afirma Walker (p. 184), a distinção feita por Zwierlein entre dois gêneros de drama para leitura, rezitationsdrama e lesedrama, partiu de uma sugestão de G. Boissier: Z. is in fact reviving Boissier's idea of a genus called by him tragédies de salon (and like Boissier and his supporters, Z. distinguishes this genus from plays which may have been written for private reading, tragédies de cabinet or Lesedramen).

${ }^{4}$ Por exemplo, Wilfried Stroh, 'Staging Seneca: the production of Troas as a philological experiment', in Fitch (ed.), Seneca. Oxford Readings in Classical Studies, Oxford University Press, 195-220, 2008; F. Dupont, Les monstres de Sénèque. Paris, Ed. Belin, 1995; S. Fortey and J. GLUCKer, Actus tragicus: Seneca on the stage, Latomus 34, 699-715, 1975. 
procura enfraquecer a dicotomia entre as duas opções aceitas pela crítica, da leitura (recitatio) e da performance teatral. Ele argumenta que as peças de Sêneca não são uniformes a esse respeito: haveria cenas que se apoiam em ação e em efeitos visuais, sendo apropriadas para o palco, e cenas que se apoiam em palavras e idéias e são estáticas quanto à ação física. ${ }^{5}$

A discussão tem como base fatores externos e internos ao texto. Entre os primeiros, o mais eloquente é a inexistência de testemunhos antigos sobre a recepção das dez peças que integram o único corpus remanescente de tragédias latinas, a despeito de haver evidências de constante atividade teatral em Roma e nas províncias, durante a época do império até o século III d.C. ${ }^{6}$ Quanto aos fatores internos ao texto, relativos a aspectos de estrutura e coerência dramática, uma primeira dificuldade está no fato de que o conhecimento atual sobre a técnica de cenografia em Roma é ainda limitado, o que acaba induzindo a que se transponha para o teatro latino a estrutura cênica que se conhece para o drama grego ático. Isso por vezes dá lugar a opiniões oscilantes ou imprecisas sobre as práticas e possibilidades da cena romana, especialmente a da época imperial. Além disso, as peças de Sêneca mostram que convenções do drama ático, como unidade de tempo e espaço, provavelmente não eram mais observadas no drama latino, e que mesmo a adoção de outras convenções formais, oriundas do drama helenístico, podia ser flexível, como a estrutura em cinco atos ou a movimentação do coro.?

O conceito de "drama para recitação" é também problemático, uma vez que não se conhece exatamente a natureza e os propósitos desse evento denominado como recitatio. Em Roma, essa prática foi introduzida por Asínio Polião, em meados dos anos 30 a.C., durante o período de transição entre a república e o império. ${ }^{8}$ A recitatio parece ter ocupado o espaço dei-

${ }^{5}$ Cf. J.G. Fitch, 'Playing...', p. 2-3: Tarrant in his editions of Agamemnon and Thyestes adopts the view that Seneca wrote for recitatio rather than performance. [...] clearly in Tarrant's criticism there is not an all-or-nothing dichotomy between the case for recitatio and the case for performance. I am going to try to blur the dividing-lines in another way, by arguing that Seneca's plays are not uniform in this respect: thet some scenes are written with the theatre in mind but one scene is written for verbal effect in such a way as to exclude theatrical performance.

${ }^{6}$ Ver P. Kragelund, 'Senecan tragedy: back on stage?', in Fitch (ed.), Seneca..., 181-194, p. 181, citando R.C. Beacham (1991).

${ }^{7}$ São exemplos disso os seguintes fatos: o tempo nas peças senequianas não é uniformemente linear; na Fedra e nas Fenícias ocorre mudança do local da ação; a peça Édipo apresenta seis atos; a presença ou ausência do coro, bem como o maior ou menor grau de sua consciência em relação aos eventos da ação são fatores que parecem subordinados à necessidade de cada momento ou mesmo à vontade do dramaturgo.

${ }^{8}$ Conforme observa Citroni, Poesia e lettori in Roma antica, Roma, Laterza, 1995, p. 
xado pela oratória pública e pelo teatro, ambos decadentes no fim da época republicana, e teria acompanhado a expansão da atividade literária e da cultura livresca. Os testemunhos antigos levam a crer que se tratava de um evento social de caráter privado e independente, não vinculado ao calendário político e religioso da cidade, posto que ocorria em uma residência ou em um auditório alugado. Era destinado quase exclusivamente à leitura de obras recém-concluídas e inéditas ${ }^{9}$, feita uma única vez, para um público letrado, frequentemente com o propósito de que o texto recebesse sugestões críticas de ouvintes, com vistas a que se estabelecesse uma versão definitiva a ser reproduzida em livro. ${ }^{10}$ A recitatio era, portanto, um evento literário, celebrava o texto escrito; era protagonizada por um escritor que, em geral ${ }^{11}$, atuava ele próprio como leitor, talvez sobre um tablado e sentado, diante de um público reduzido, constituído principal e necessariamente por amigos convidados. Não havia lugar para o público imperito e a presença dos convidados era ditada por normas de obrigação social. De modo geral, a audiência era em parte constituída por uma elite de escritores que, por vezes, também eram membros da classe senatorial e equestre. Eram variados os gêneros discursivos dos textos lidos: historiografia, oratória epidítica, poesia épica, lírica e dramática. $\mathrm{O}$ foco da atenção eram as qualidades técnicas da composição, sobretudo as relativas à elocução. ${ }^{12}$ Esses dados, porém, não encerram um quadro completo sobre a prática da recitatio em diferentes épocas e, diante do que se sabe, parece incoerente afirmar que se compunham obras com vistas exclusivamente à recitação, sendo esse evento apenas uma das formas de transmissão de um texto, e mais importante que isso, uma forma que geralmente preludiava a publicação em livro. ${ }^{13}$

34, n. 5, a recitação, referida por Sêneca, o Velho (Controvérsias 4, Praefatio, 2) como novidade iniciada por Asínio Polião, foi possivelmente introduzida em Roma bem antes disso, por volta do fim do século II a.C. e início do século I a.C., no quadro do processo de helenização do costume cultural romano.

${ }^{9}$ Segundo Citroni, Poesia e lettori ..., p. 10-11, as recitações eram normalmente de um livro concluído ou quase concluído, e os casos de recitações públicas de obras que já circulavam em forma de livro eram muito raros: Le "recitazioni" sono di norma recitazioni di un libro - già compiuto o in corso di ultimazione -, non di un testo che prescinde dalla forma libraria. Per lo più sono intese come saggi provvisori o come presentazioni in anteprima di testi che troveranno la loro forma definitiva e la loro piena realizzazione nel libro.

${ }^{10}$ Ver F. Dupont, 'Recitatio and the reorganization of the space of public discourse', in T. Habinek \& A. Schiesaro (ed.), The Roman cultural revolution, Cambridge, University Press, 44-59, 2000, p. 46, 48-49, 56-59.

${ }^{11}$ Plínio, o Jovem (Ep.9.34.1-2) diz que lia mal seus poemas e delegava a leitura a um liberto seu.

${ }^{12}$ As fontes em que se descreve a recitatio são principalmente as obras de Marcial, Juvenal e Plínio, o Jovem.

${ }^{13}$ Cf. R.J. Tarrant, Seneca's Thyestes, Atlanta, American Philological Association, 1985, 


\section{Declínio da tragédia latina no I a. C.}

Desde as últimas décadas da época republicana, houve um crescente desinteresse do público dos teatros pela tragédia e a preferência por espetáculos meramente visuais ou de fraco conteúdo intelectual. ${ }^{14}$ Parece ter havido uma forte contraposição entre, de um lado, o teatro público, em que floresceram gêneros como o mimo e a pantomima, os quais ocorriam paralelamente a espetáculos esportivos e circences variados e, de outro lado, o drama literário, cultivado em círculos restritos por uma camada letrada da sociedade romana, ao que parece, atraída justamente pela excelência oratória e pelo conteúdo literário, certamente enfatizados no poema trágico da época de Augusto. ${ }^{15}$ Em um importante artigo sobre a evolução da

p. 15: But to pose the question exclusively in terms of theatrical performance vs. recitation is to obscure an essential fact. Whatever form of public exposure Seneca may have planned for his tragedies could only have been the beginning of their career, a preliminary to the ultimate goal of publication.

${ }^{14}$ Conforme testemunho de Cícero (Fam., 7, 1), no fim da república as encenações de tragédias davam grande destaque ao espetáculo visual em detrimento do texto, com a adoção do aparato e das exibições extravagantes inspirados nos triunfos militares. Os comentários de Cícero indicam o desinteresse que havia na parcela culta do público por boa parte das atrações dos espetáculos teatrais. A imagem negativa do teatro tornou-se depois um lugar-comum na literatura latina da época de Augusto. Leia-se, entre outras, esta passagem de Horácio (Ep. 2, 1, 200-207):
[...] Nam quae pervincere voces
evaluere sonum, referunt quem nostra theatra?
Garganum mugire putes nemus aut mare Tuscum:
tanto cum strepitu ludi spectantur et artes
divitiaeque peregrinae; quibus oblitus actor
cum stetit in scaena, concurrit dextera laevae.
"Dixit adhuc aliquid?" "Nil sane." "Quid placet ergo?"
"Lana Tarentino violas imitata veneno".
[...] De fato, que vozes puderam
vencer o barulho que nossos teatros reproduzem?
Ias achar que mugia a floresta de Gargano ou o mar toscano,
tamanho o estrépito com que são apreciadas as exibições e as artes
e adornos estrangeiros, dos quais, recoberto o ator,
quando em pé no meio da cena, as mãos o aplaudem.
"Ele disse algo até agora?" - "Nada." - "O que os agrada então?"
"A lã que, com a tintura de Tarento, imita a cor das violetas".

${ }^{15}$ Cf. TARrant, Seneca's Thyestes, p. 13: It is true that the Romans, following the Hellenistic Greeks, classed tragedy with epic as the most prestigious of literary genres. The theater in Rome, however, never attained the high esteem it had enjoyed in Greece, and a close involvement with the stage would have been thought positively dishonorable for a Roman of high social standing. 
tragédia latina, Goldberg ${ }^{16}$ defende que foi positiva a influência da retórica, particularmente a da declamação, na tragédia romana: o molde do discurso declamatório aplicado à tragédia teria afirmado a primazia da linguagem (portanto, do conteúdo) sobre o espetáculo. Teria-se resgatado, assim, o elemento intelectual do drama, em detrimento do espetacular e circence. ${ }^{17}$ Em decorrência disso, o sistema literário em que se inseria o drama latino teria passado por uma reconfiguração, que certamente levou a mudanças nas características do gênero dramático. Pode-se crer que a tendência que se fortaleceu foi a prevalência do texto sobre a encenação, e daí, da leitura sobre a dramatização. Em outras palavras, o refinamento técnico da poesia latina nesse período teria abrangido também o drama, o que certamente resultou em uma considerável alteração na condição do autor dramático e de seu público, bem como no modo de recepção do texto dramático. ${ }^{18}$

Deve-se ter em vista, portanto, que as peças de Sêneca são representativas dessa nova configuração do drama latino, estabelecida no início da época imperial. Trata-se de um texto de caráter eminentemente literário, subordinado aos principais modelos da poesia latina da época de Augusto, o que é observável tanto na elocução quanto em expedientes da técnica poética. Além disso, eles foram produzidos em um período em que a cultura literária e livresca já estava bastante avançada na sociedade romana, de modo que é coerente pensar que sua destinação principal e final teria sido o livro, tal como ocorria com outros gêneros como a épica ou a lírica, sendo secundária qualquer modalidade de performance, seja em uma leitura dramatizada, seja em uma encenação, envolvendo parcial ou integralmente o texto dramático. ${ }^{19}$

${ }^{16}$ S.M. GoldBerg, The fall and rise of Roman tragedy, TAphA 126, 265-85, 1996, p. 276.

${ }^{17}$ Cf. GoldBerg, The fall..., p. 272-73: A distinction between popular entertainment and literary theater that would have been as incomprehensible to second-century Romans as to fifth-century Athenians now becomes an increasingly significant fact of Roman stage history. Under the Principate, literary drama began to abandon public theaters for the more intimate (and more aristocratic) confines of smaller roofed halls and private homes. Recitation rather than fully staged performance became the norm, the kind of performance long established for the presentation of Latin literary works.

${ }^{18} \mathrm{O}$ fato de que Lúcio Ácio, morto por volta de 90 a. C., foi, ao que se sabe, o último tragediógrafo latino "profissional" pode ser visto como emblemático do declínio do gênero trágico. Depois dele, o perfil predominante do tragediógrafo passou a ser ou o de intelectuais, como, entre outros, Júlio César, Quinto, irmão de Cícero e Otaviano, ou o de escritores polígrafos, que se dedicaram pontualmente ao drama, como Lúcio Vário, Ovídio e o próprio Sêneca.

${ }^{19}$ Citroni (Poesia..., p. 10) ressalta a dificuldade que há em distinguir entre a leitura em uma recitação e a leitura particular: Va anche considerato che nell' antichità la stessa lettura personale dei testi letterari era fatta solitamente ad alta voce e che era diffusa la pratica di farsi leggere i libri da uno schiavo specializzato nella funzione di lettore (anag- 
Quanto a isso, aliás, sabe-se que em Roma, no período imperial, era mais frequente nos teatros a apresentação de "árias" extraídas de tragédias ou de cenas trágicas que continham um clímax, do que a apresentação de peças inteiras ${ }^{20}$. Autores de tragédia do século I d.C. podem ter trabalhado de modo diferenciado na composição de cenas desse tipo, com vistas a maior probabilidade de sua encenação isolada. Há também evidências de que, na época imperial, a performance de tragédia, ou de cenas trágicas, se dava na forma de pantomima, gênero de dramatização dançada, que envolvia também extratos de outros gêneros poéticos, como a épica ou a elegia. ${ }^{21}$

Independentemente de terem sido encenadas ou não, em vários aspectos a escrita das peças de Sêneca mostra-se em conformidade com as convenções teatrais certamente em voga na época imperial. ${ }^{22}$ Nelas aparecem elementos de composição tradicionais no drama, como relatos, monólogos, monodias, diálogos em esticomitia e antílabe, falas à parte, monólogos de entrada e exposição de cenas interiores. Em alguns pontos, é possível inferir do texto a sugestão do emprego de artifícios cênicos, como, por

nóstes), magari in presenza di qualche familiare o amico intimo, o durante un banchetto: perciò la distinzione tra lettura personale e recitazione non è del tutto netta, e l'attenzione dell'autore per gli effetti fonici, per gli effetti "recitati" del testo era comunque rilevante. ${ }^{20}$ Ver A. Boyle, Seneca's Oedipus, edited with Introduction, Translation and Commentary, New York, Oxford University Press, 2011, p. xxxiv e xli, o qual cita H. A. Kelly, Ideas and forms of tragedy from Aristotle to the Middle Ages. Cambridge, 1993; ver também Goldberg, The fall..., p. 269, n. 7. Marica Frank, Seneca's Phoenissae. Leiden, E. J. Brill, 1995, p. 42, observa o seguinte: It seems likely that Seneca expected the plays to be known in their entirety only through written copies, although extracts or individual scenes might be presented on stage or at a recitation or dramatised reading. A autora ainda complementa em nota (n. 180): If Seneca had in mind the possibility that his plays might be recited or performed piecemeal, it may explain the much-criticised importance of the individual scene over the overrall plan and development of the plot.

${ }^{21}$ Cf. R. Ferri, Octauia. A play attributed to Seneca, edited with Introduction and Commentary by Rolando Ferri. Cambridge, University Press, 2003, p. 56, n. 138. Conforme destaca também A. Boyle, Seneca's Oedipus, Introduction, p. xli: Extracts from the tragedies could also had served as libretti for tragoediae cantatae or (like Virgil's Aeneid and Ovid's poemata) for the sung accompaniments to tragoediae saltatae, the pantomimic dance. Indeed aspects of Seneca's own dramaturgy - especially descriptions by the chorus or another actor of the movements and emotions of impassioned women-may have been influenced by pantomime itself. Ovídio (Tr. 2, 1, 520) menciona a representação dançada de seus poemas: Et mea sunt populo saltata poemata saepe, "E meus poemas também foram muitas vezes dançados para o público".

${ }^{22}$ Quanto a isso, é bastante pertinente a seguinte observação de H.M. Hine, [untitled Review], The Journal of Roman Studies 77, 256-58, 1987, p. 256-57: it is implicit in recent discussions of the staging problem that one must get away from intentionalist talk of writing 'for the stage' or 'for recitation' or 'for reading', because in all probability Seneca simply thought in terms of writing tragedies. 
exemplo, a plataforma giratória denominada eggkyclema, no Tiestes e no Hércules louco, o uso de um mecanismo de elevação (mechané) na cena final de Medeia ${ }^{23}$ na peça Fedra, a existência de uma alusão a mudança no espaço cênico, da cidade para a floresta, sugere o emprego de cenário formado por paineis móveis..$^{24}$ Em contrapartida, um dos aspectos que reduzem o potencial de espetáculo teatral dessas peças, considerando o perfil do público romano da época imperial, é a complexidade da linguagem poética empregada por Sêneca, gerada entre outros fatores, pelo estilo elevado e alusivo, pela densa relação intertextual com modelos literários, notadamente os não dramáticos, pela prevalência do discurso sobre as ações, além do fundo filosófico associado aos enredos..$^{25}$ Tais fatores, vale reiterar, estabeleciam uma forte contraposição com gêneros teatrais praticados nos grandes teatros, como o mimo e a pantomima, nos quais o texto tinha pouca importância frente, respectivamente, à ação e à coreografia. ${ }^{26}$

\section{Mescla de gêneros no drama senequiano}

Vários estudos que examinaram a questão dos modelos da poesia de Sêneca já demonstraram que, ao contrário de uma crença sedimentada na crítica desde o século XIX até meados do XX, a relação da tragédia senequiana com o drama ático é bastante indireta, mesmo quando se consideram modelos de Eurípides. O trabalho mais importante sobre isso continua sendo o extenso artigo de R.J. Tarrant, Senecas drama and its antecedents, em que se analisam vários aspectos da técnica dramática de Sêneca, certamente provenientes do drama helenístico, sendo aventada a hipótese de que possivelmente também estariam presentes no drama latino da época e $\mathrm{Au}-$

${ }^{23}$ Sen. Thy. 901; Her. F. 413; Med. 1025.

${ }^{24} \mathrm{O}$ advérbio huc (Sen. Phaed. 431), na fala de Hipólito, que havia se retirado para as matas, é um dos itens que denotam a mudanca de cenário: Quid huc seniles fessa moliris gradus, "Por que moves para cá, fatigada, os teus passos idosos".

${ }^{25}$ G.A.Staley, Seneca and the idea of tragedy, Oxford, University Press, 2010, p. 113, resume a importância da linguagem em Sêneca com o seguinte comentário: The "spectacle" of Senecan tragedy is not created through costume or scenery but through the images that readers or listeners create for themselves in their minds, spurred by Seneca's verbal paintings. In Seneca, as in Longinus, the instrument of phantasia is to be found in the text; Longinus regularly cites the scripts of Sophocles and Euripides, but he never mentions performance. Even Aristotle acknowledged (Poetics 1453b3-6) that the words alone were all that was necessary to create the appropriate tragic effect as long as events were structured properly. ${ }^{26}$ Ovídio (Tr. 2, 1, 497-520), num contexto apologético, ressalta o conteúdo imoral dos mimos e a atitude tolerante de Augusto; assinala também o sucesso desse tipo de espetáculo (v. 506): Plauditur et magno palma fauore datur, "Aplaude-se e com grande mercê concede-se a palma". 
gusto. ${ }^{27}$ Esses poderiam ter sido os modelos diretos de Sêneca. No entanto, diante do quase completo desaparecimento do drama helenístico e o da época de Augusto, ganha maior importância a relação das peças senequianas com modelos latinos não dramáticos, a qual é bastante evidente, notadamente com a obra de Virgílio e Horácio e, mais ainda, com a de Ovídio.

Um dos fatos marcantes da poesia de Ovídio, derivado do vínculo de sua técnica poética com a de poetas helenísticos, em particular a de Calímaco, é a mescla de gêneros nela praticada. Em relação à literatura grega, uma síntese sobre o modo de os autores operarem com os gêneros foi proposta por Rossi em um importante estudo sobre os gêneros literários na Antiguidade clássica. ${ }^{28}$ Resumindo a fórmula proposta por ele, no período arcaico da literatura grega as leis relativas aos gêneros não estavam escritas, mas eram respeitadas; em seguida, no período clássico, passaram a ser escritas, mantendo-se respeitadas; já no período helenístico, estavam escritas, porém, deixaram de ser respeitadas. ${ }^{29}$

Esse aspecto da técnica poética praticada na poesia grega já no começo da época helenística, resultou no que foi denominado modernamente como cruzamento ou mescla de gêneros. ${ }^{30}$ Entre os latinos, é observável

${ }^{27}$ Como ressalta Boyle (Seneca's Oedipus, p. xxix-xl), Tarrant (Senecan Drama and its antecedents, HSCP 82, 213-263, 1978) mostrou que o teatro latino da época republicana assimilou práticas e convenções do drama helenístico, particularmente da Comédia Nova dos séculos IV e III a.C.: estrutura em cinco atos, amplo uso de falas à parte, monólogos de entrada, saídas e reentradas do coro, saída de personagem para engendrar ação futura. Essas práticas possivelmente já estavam padronizadas no teatro latino na época de Augusto, quando a influência helenística na poesia romana foi mais intensa. O drama de Sêneca certamente teve como modelos diretos os dramas da época de Augusto. Igualmente, H.M. Hine (Review..., 1987, p. 256) resume: An article of Tarrant's (Senecan Drama...) has shown how in a number of respects Seneca's plays continue earlier developments of dramatic technique in the Hellenistic and Roman theatre.

${ }^{28}$ L.E. Rossi, I generi letterari e le loro leggi scritte e non scritte nelle letterature classiche, London, University of London, Institute of Classical Studies, Bulletin n. 18, 1971. ${ }^{29}$ Quando se trata de aspectos característicos da poesia helenística, é importante levar em conta uma observação como a de A. KöRTE \& P. HÄndEL (La poesia helenística, Barcelona, Labor, 1973, p. 222), sobre não ter havido um programa estético predominante durante o helenismo, nem numa determinada época dele, envolvendo vários autores. As formas narrativas - os autores, nesse ponto, tratam em particular da poesia épica - praticadas no helenismo são muito variadas, nem sequer os conteúdos obedecem a uma regra simples. Um período de quase três séculos (323/30 a.C.) com numerosos escritores espalhados geograficamente (os grandes centros culturais eram Alexandria, Pérgamo, Siracusa, Cós, Tarento, Atenas) oferece um panorama igualmente variado e múltiplo. Em razão disso, convém sempre delimitar o autor a que determinada prática estaria relacionada ou restrita. ${ }^{30}$ A expressão "Kreuzung der Gattungen” foi empregada por Wilhelm Kroll, Studien zum Verständnis der römischen Literatur, Stuttgart, 1924. 
o emprego dessa técnica na obra de Virgílio, porém ela aparece de forma mais ampla e caracterizada na obra de Ovídio. ${ }^{31}$ Por conseguinte, a própria relação estreita entre a poesia de Sêneca e a obra desses dois poetas latinos, é um dos fatores que ajudam a fundamentar a hipótese da prática da mescla de gêneros na tragédia senequiana. De fato, a ampla absorção de elementos formais e temáticos de outros gêneros - da épica, da lírica e também da oratória declamatória - , imprime a essas peças uma forma bastante complexa, uma vez que os limites do gênero se mostram em geral alargados ou sem nitidez. Conforme se propõe aqui, as tragédias de Sêneca não são genericamente uniformes e esse seria um fator que afetaria o caráter teatral de muitas cenas ao longo de uma peça. ${ }^{32}$

\section{Tragédia e épica}

Para exemplificar casos de intersecção com elementos da poesia épica, que são os mais frequentes, pode-se considerar, primeiramente, o uso de símiles nas partes dialogadas. Símiles extensos, de tipo épico, evitados, de modo geral, na tragédia grega, ocorrem nas peças de Sêneca, nos momentos de clímax emocional. Um artifício retórico como esse contribui para o modo narrativo predominante nas peças senequianas, em detrimento do modo dramático, que predomina nas gregas: ninguém, num estado emocional intenso, usaria amplos símiles para descrever seu transtorno, como já observou uma estudiosa de elementos descritivos no drama de Sêneca. ${ }^{33}$ Um exemplo representativo ocorre no Tiestes (497503), numa fala de Atreu:

${ }^{31}$ Entre os trabalhos que trataram desse aspecto da obra de Ovídio, pode-se destacar livro de IsABElle Jouteur, Jeux de genres dans les Metamorphoses d'Ovide, Louvain, Peeters, 2001. ${ }^{32}$ Sobre isso, é interessante aproximar um comentário de Aldo Setaioli em um longo ensaio sobre o estilo senequiano na obra em prosa: Seneca e lo stile, ANRW, 776-858, 1985, p. 814-815. Os fatos apontados por ele parecem em boa medida pertinentes também para a tragediografia de Sêneca: [...] La posizione filosofica del Cordovano, che lo portava ad affermare recisamente la prevalenza delle res sui verba, gli permetteva di staccarsi dal formalismo retorico, che subordinava al contrario il pensiero allo stile; la stessa tendenza dello stoicismo a non dare eccessiva importanza alla distinzione fra i generi letterari, ciascuno dei quali aveva le sue regole fisse, poteva contribuire a lasciare maggior libertà all'individualità dell'autore. D'altro canto il gusto barocco dei tempi di Seneca faceva sì che la retorica contemporanea, tutta volta ad ottenere l'effetto, tendesse, come ha ben sottolineato il Norden [Die antike Kunstprosa I. Berlin 1915, p. 280], non a rifarsi alle regole canoniche dell'oratoria, ma, nella sua ricerca dell'espressione a tutti i costi originale, a crearsi essa stessa le sue regole, rompendo così la tradizione classica.

${ }^{33}$ Cf. Victoria T. LARson, The role of description in senecan tragedy, Frankfurt am Maim, Peter Lang, 1994, p. 62. R.J. Tarrant (Seneca's Thyestes, p. 162) considera o uso de símile 
Vix tempero animo, uix dolor frenos capit. Sic, cum feras uestigat et longo sagax loro tenetur Vmber ac presso uias scrutatur ore, dum procul lento suem odore sentit, paret et tacito locum rostro pererrat; praeda cum propior fuit, ceruice tota pugnat et gemitu uocat dominum morantem seque retinenti eripit. Cum sperat ira sanguinem, nescit tegi;

Mal me contenho, a dor mal aceita os arreios. Assim, o cão da Úmbria, no rastro de feras, atado a longa guia, apura o faro e trilhas perscruta, enquanto sente longe o lento odor do javali; vasculha o local, obediente e calado; quando a presa lhe fica mais perto, retesa todo e empuxa e com um gemido chama o dono que demora e lhe retém o arrojo.

Diante do sangue, a ira não sabe ocultar-se;

Igualmente o emprego de écfrases extensas é uma marca do gênero épico. ${ }^{34}$ No Hercules furens, terceiro ato, um elemento do argumento central (o intento de matar o tirano Lico) é ofuscado por um elemento ecfrástico: a narrativa de Teseu contendo uma longa descriptio inferorum, descrição das regiões infernais, cujo modelo é Virgílio. ${ }^{35}$ A inserção de longas seções narrativas no diálogo dramático joga com a expectativa dos ouvintes / leitores relativa ao gênero dramático. Em uma encenação, a extensão de falas com conteúdo descritivo ou narrativo rompe a verossimilhança do diálogo; a figura do interlocutor se apaga e a interlocução se desloca em direção da audiência. Ou seja, há uma redução da função dramática de uma fala desse tipo, ao mesmo tempo em que adentra o campo do gênero narrativo, ganha independência e parece dirigida à audiência ou ao leitor. ${ }^{36}$

"épico" numa fala dramática uma das mais típicas características da tragédia de Sêneca. A ocorrência é frequente: Ag. 138-40; Phaed. 181-83, 382-84, 940-42; Tro. 572-76, 794-98; entre os mais extensos estão Thy. 497-503 e Med. 926-28, 937-44.

${ }^{34}$ No livro 6 da Eneida, são descritas, em elaborada écfrase, as portas do templo de Apolo em Cumas. A écfrase, enquanto elemento da poesia homérica, incide mais restritamente sobre objetos de arte: o escudo etc. (cf. A. KÖRTE \& P. HÄNDEL, La poesia helenística, p. 169). ${ }^{35}$ Ver J.G. Fitch, Seneca's Hercules Furens, Ithaca, Cornell University Press, 1987, p. 46-47. ${ }^{36}$ Outro exemplo notável é o relato do mensageiro Euríbates (Ag. 421-578). Conforme observa Victoria Larson, The role..., p. 62: ...the Senecan character becomes, as it were, a narrator of his or her own situation, establishing a link with the audience and an objective distance from the other characters which breaks down the limits of the self-contained 
Na peça Troianas, quando termina o primeiro ato, o coro de mulheres troianas deve continuar em cena para servir de interlocutor para o mensageiro Taltíbio, na primeira cena do segundo ato. Após a narrativa de Taltíbio sobre a aparição do espectro de Aquiles e a exigência do sacrifício de Políxena para liberar a esquadra grega, estranhamente não há reação do coro. Taltíbio termina sua fala e sai de cena sem que isso seja assinalado, ocorrendo, logo em seguida, a súbita entrada de Pirro e de Agamêmnon, que aparecem já em plena discussão, introduzida in medias res, sobre o sacrifício de Políxena, o que sugere que eles teriam testemunhado a aparição de Aquiles. O silêncio do coro depois do relato de Taltíbio pode ser explicado como decorrente do uso de modelos épicos latinos. Na fala de Taltíbio sobre a morte de Políxena, o modelo teria sido a narrativa ovidiana sobre esse tema, nas Metamorfoses, 13.439-52. Nesta, com o verbo dixit (v. 449), o narrador pontua o fecho da fala do fantasma de Aquiles, reportada em estilo direto, e passa de imediato para a descrição do sacrifício:

'[...] utque meum non sit sine honore sepulcru
placet Achilleos mactata Polyxena manes!'
Dixit, et inmiti sociis parentibus umbrae,
rapta sinu matris, [...]
ducitur ad tumulum diroque fit hostia busto.

“[...] e para que meu sepulcro não fique sem honras, apraz aos Manes de Aquiles a imolação de Políxena!" Disse, e obedecendo ao cruel espectro seus aliados, arrancada [sc. Políxena] do seio da mãe, [...] é conduzida ao túmulo e torna-se vítima da tumba atroz.

Ao lado da imitação formal de expressões ovidianas, Sêneca teria também incorporado a seu texto dramático o expediente da narrativa épica conforme o qual se deixa uma fala, por assim dizer, sem resposta imediata e se corta para a cena seguinte tão logo se tenha completado o evento enfocado em uma seção narrativa. A adoção dessa prática, nessa cena das Troianas, pode, portanto, ser vista como o fator determinante da ruptura da continuidade dramática, que exigiria a reação do coro após o relato de Taltíbio.

world essential to the dramatic mode and sets up a relationship with the audience which properly belongs to the narrative mode. 


\section{Tragédia e lírica}

O coro senequiano normalmente apresenta fraca integração com as partes dialogadas. Sua intervenção é em geral súbita e alheia aos eventos do enredo, e por vezes nem mesmo sua identidade se mostra com nitidez. ${ }^{37}$ Enxertado entre as seções iâmbicas da peça, o canto coral apresenta formas variadas, desde a forma de um canto em ritmo anapéstico, tradicional no drama, até a de um epitalâmio literário, como o coro I de Medeia (56115), ou a de um hino literário, como o coro II de Agamêmnon (310-411). Muitos cantos assemelham-se formal e tematicamente a odes de Horácio, com largo emprego dos metros eólicos adaptados por aquele poeta. Terminado o intermezzo lírico, nada indica que o coro permaneça presente ou se retire; ele antes parece desfazer-se de modo instantâneo. ${ }^{38} \mathrm{Se}$, por um lado, o súbito silêncio, ou "desligamento", do coro pode causar uma ruptura problemática em uma encenação, por outro, a mesma dificuldade por vezes ocorre admitindo-se tanto sua permanência em cenas subsequentes ao canto coral, quanto sua presença durante a cena precedente, uma vez que também o alheamento desse personagem coletivo pode gerar variados graus de incoerência. ${ }^{39}$ Tal distância e isolamento das partes corais relativos aos eventos do enredo, em combinação com características formais e genéricas de muitos desses cantos, reforçam seu caráter de poemas autônomos dentro da peça, onde figuram como formas entremeadas com o poema dramático e que incisivamente o interrompem, comprometendo o jogo teatral pela alternância genérica.

\section{Tragédia e declamação}

Conforme observa Winterbottom, a influência da poesia sobre o discurso declamatório não era menos marcada do que a influência deste sobre

${ }^{37}$ É o caso do coro I das Troianas (372-408), sobre cuja identidade os próprios manuscritos discordam, uns indicando que é constituído de soldados gregos, outros, de mulheres troianas, ambos os grupos sendo pouco verossímeis, em vista da temática filosófica desenvolvida.

${ }^{38} \mathrm{O}$ coro senequiano só permanece na cena dialogada subsequente quando não há outro interlocutor disponível.

${ }^{39}$ Em uma recente encenação do Agamêmnon (Paris, Comédie Française, 21/mai - 23/ jul/2011, mise en scène de Denis Marleau), o coro figurou como um personagem "vidéo": as faces dos coreutas foram projetadas em um pano de fundo da cena durante a declamação das odes corais. Terminada a "fala" do coro em vozes sobrepostas, desaparecia sua imagem, finalizando-se a projeção na tela. 
a poesia. ${ }^{40}$ As assimilações recíprocas entre poesia e declamação podem ser observadas tanto no campo da invenção, quanto no da elocução, ou seja, de um lado, em elementos temáticos e esquemas argumentativos, compartihados por oradores e poetas, de outro, em itens característicos de ornamentação e de estilo. ${ }^{41}$ Desse modo, a inserção de materiais provenientes da poesia, prática adotada pelos declamadores, gerava uma forma discursiva híbrida, e esta, em sentido inverso, deve também ter tido reflexos sobre a prática compositiva de poetas da época imperial.

Interessa ressaltar, tendo-se em vista o drama, o fato de que a actio declamatória era certamente confinante com a atuação dramática: o declamador, ao tratar de uma questão judiciária, na chamada controvérsia, podia falar ora na pessoa do promotor, ora na do próprio acusado, ou então assumia o papel do advogado ${ }^{42}$. Na suasória, modalidade deliberativa, ele podia optar ora por dar conselhos favoráveis, ora contrários a um determinado curso de ação, assumindo o papel ora de um conselheiro imaginário, ora o de uma personagem a deliberar. O declamador, em certa medida, acumulava as funções de autor e de ator: ${ }^{43}$ dirigia-se a uma audiência que já conhecia previamente os temas e interessava-se pelas variações e pelos recursos elaborados pela imaginação de cada orador para surpreender e emocionar os ouvintes, persuadi-los em diferentes direções e impressionálos com artifícios de elocução.

Em vista da mencionada interrelação entre declamação e poesia, é justo considerar o reflexo desses expedientes da arte declamatória na composição da poesia dramática senequiana, ainda mais em se tratando de um autor cuja formação se deu no seio de um círculo renomado de declamadores. ${ }^{44}$ De fato, a presença de recursos de elocução e de formas

\footnotetext{
${ }^{40}$ M. Winterbottom, Roman declamation, extracts with commentary, Bristol, Bristol Classical Press, 1980, p. 61.

${ }^{41}$ Há várias passagens da obra de Sêneca, o Velho, em que se evidencia o apreço dos declamadores pelos versos ovidianos, e.g. Con. 10.4.25; Con. 3.7 (excerpta).

${ }^{42}$ Quintiliano, Declamações menores 260.61 .12 (Ritter): in plerisque controversiis plerumque hoc quaerere solemus, utrum ipsorum persona utamur ad dicendum, an advocati: vel propter sexum, sicut $<$ in $>$ feminis, vel propter aliquam alioqui vitae vel ipsius, de quo quaeritur, facti deformitatem, "Em numerosas controvérsias, isto com frequência costumamos indagar, se falamos em nossa própria pessoa ou na do advogado: seja devido ao sexo, como no caso das mulheres, ou senão, a alguma viciosidade de comportamento ou até do próprio fato sobre o qual se faz a demanda".

${ }^{43}$ Cf. M.L. Clarke, Rhetoric at Rome. A historical survey. London, Routledge, 1953, p. 96: A good declaimer was a virtuoso, with much of the actor about him.

${ }^{44}$ Segundo S.F. Bonner (Roman declamation in the late Republic and early empire, Liverpool, Liverpool University Press, ${ }^{2} 1969$, p.162) e H.V. Canter (Rhetorical elements in the
} 
discursivas próprios desse tipo de oratória é um aspecto constantemente destacado pela crítica, que, como já se disse no início, por vezes o condena em razão de uma alegada artificialidade, que prejudicaria o caráter teatral das peças. ${ }^{45}$ Tais elementos oratórios aparecem com particular relevo em uma das cenas do segundo ato, bastante padronizada, que contém um debate relativo ao conflito retratado no enredo: ali motivos temáticos e estruturas argumentativas presentes em controvérsias e suasórias invariavelmente aparecem na composição das falas.$^{46}$ Nas demais cenas dialogadas, a inserção de extensas descrições é também um procedimento de composição provavelmente resultante do influxo da prática oratória da época imperial. A descriptio, como se sabe, era muito valorizada entre os declamadores enquanto um color poeticus proveniente da poesia épica, para o qual os declamadores latinos encontravam modelos sobretudo nas obras de Virgílio e Ovídio. ${ }^{47}$

tragedies of Seneca, Studies in Language and Literature, X, 1, The University of Illinois, 1925, p. 22-23), do conjunto de enredos que a tragédia grega e latina oferecia, Sêneca certamente selecionou os de maior potencial para um tratamento declamatório, por oferecerem material para se retratar cenas de horror, selvageria e de emoções intensas, tal como recomendava o declamador Latrão (cf. Sen. Con. 1.1.21): Colorem...Latro aiebat hunc sequendum, ut grauissimarum iniuriarum inexorabilia et ardentia induceremus odia Thyesteo more, "Latrão aconselhava a imaginar este color: que introduzíssemos ódios implacáveis e ardentes, motivados por injúrias gravíssimas, tal como Tiestes"). Atendiam melhor a esse interesse os enredos que continham assassinato de crianças: de filhos pelos pais, como em Medeia e Hércules louco, de sobrinhos pelo tio, como em Tiestes, de jovens nas Troianas, ou assassinato de adultos, como da esposa, em Hércules louco, do marido, em Agamêmnon.

${ }^{45}$ Um exemplo de frase contundente, típica do estilo declamatório, é esta em que a heroína Fedra fala para si mesma: Morere, si casta es, uiro; / si incesta, amori, "Morre, se és casta, por teu marido; / se és incasta, por teu amor" (Fed. 1184-85).

${ }^{46}$ Ver, por exemplo, Sen. Tro. 203-352; especialmente os versos 326-41 ('Políxena debe ser sacrificada ou não?') assemelham-se a uma passagem de Sêneca, o Velho, Suas. 3. A fala de Medeia (Med. 236-51) apresenta elementos de uma controvérsia. Em Ag. 203-25, a réplica da ama é, segundo Tarrant (Seneca Agamemnon, Cambridge, University Press, 1976, p. 212) uma "suasória em miniatura". Há, porém, vários exemplos também em outras seções das peças: Phoen. 535-85 (suasória em verso); Tro. 642-62. (prosopopéia de Andrômaca). Em Thy. 546-622, desenvolve-se a tese Rusticane uita an urbana potior? (cf. Quint. Inst. 4, 24); em Med. 301-379, o coro desenvolve a tese An nauigandum ("Deve-se navegar?"), equivalente a Sen. Suas. 1, em que Alexandre delibera an Oceanum nauiget ("se deve navegar pelo oceano").

${ }^{47}$ Por exemplo, Verg., A. 1.84-156; 3.190-210; 5.8-34; Ov. Met. 11.461-572. A descriptio fazia parte dos exercícios escolares (progymnasmata). Ela se fixou, entre os declamadores, como um tipo predileto de digressão e, apesar de ser um elemento ornamental, chegou a figurar como uma das partes do discurso declamatório. Segundo Bonner (Roman declamation..., p. 59-60), os declamadores tinham predileção por descrições de tempestade 
O tratamento das personagens constitui ainda outro um aspecto que parece modelado pela prática oratória. As personagens senequianas operam dentro de um repertório restrito de lugares-comuns, falam com uma linguagem permeada de expressões formulares e vivem estados psíquicos bem semelhantes. ${ }^{48}$ A oscilação muitas vezes paradoxal no comportamento e na linha de ação de certas personagens também as aproxima ao contexto declamatório. Como se dá, por exemplo, no caso da ama, na peça Fedra: num primeiro momento, em um discurso formalmente similar a uma suasória, ela defende eloquentemente um argumento filosófico-moral contra a paixão amorosa revelada pela heroína e, em seguida, adere à causa de sua senhora e dirige a Hipólito um discurso, também em forma de suasória, em favor da relação amorosa com sua madrasta. Igualmente, nas cenas de embate verbal, o jogo de contraposição de argumentos entre dois personagens parece muitas vezes refletir o contexto do jogo declamatório, observado nas controvérsias, no qual se defendia ora uma parte, ora outra de um mesmo litígio. No segundo ato da peça Agamêmnon, que é formado por duas cenas justapostas, há uma súbita inversão no estado psicológico de Clitemnestra: na primeira cena (v. 131-225) ela aparece em plena fúria, decidida a atacar o marido; já na cena seguinte (v. 226-309), torna-se hesitante, defendendo a posição contrária à anterior.

marítima, cenas de horror, desmaios e de bebedeira. Encontram-se vestígios de descrição de tempestade já nos antigos dramas latinos, particularmente no Aegisthus, de Lívio Andronico, e na Clytemestra, de Ácio. Conforme recorda Larson (The role..., p. 91-93), Lívio Andronico foi o primeiro a introduzir relato de tempestade na poesia latina: no Aegisthus e na sua tradução da Odisséia. Pacúvio, no Teucro, oferece o aparato completo da descrição romana de tempestade. Ácio também contribuiu para a tradição desse tipo de relato na poesia latina: Clytemestra 237; Medea 183-185; 239, 381-394, 573-577 (Ribbeck). No entanto, os tratamentos de Virgílio e Ovídio tornaram-se paradigmáticos; este último, além de emular com Virgílio nas Metamorfoses, empregou esse tópico descritivo também em outras obras: Fastos 3.581-600; Tristia, 1.2.14-62; 1.11.13-44. Na declamação, referências a tal descrição são feitas em Sen. Con. 7.1.4; 7.1.10; 7.1.26; Suas. 3.2. Vale lembrar que, em Sêneca, além do tratamento no Agamêmnon (421-578), em que ele emula com Virgílio e Ovídio, há outro exemplo na Fedra (1007-1034). Cenas de desmaio e de bebedeira ocorrem, respectivamente, no Agamêmnon (775-78, 786-90) e no Tiestes (908-69).

${ }^{48}$ É possível que tais características tenham se estabelecido já no drama grego do período helenístico, e podem, em certa medida, ser detectadas em fragmentos do drama latino da época da república. Porém, em vista dos paralelos na caracterização psicológica das personagens declamatórias e senequianas, o modo homogêneo de expressão e o perfil não realista destas últimas explica-se melhor como decorrente do modelo declamatório, e não de mera adesão à técnica dramática dos antigos tragediógrafos latinos, cujas obras não eram em geral apreciadas pelos escritores da época imperial. Ver Aulo Gélio (Noites Áticas 12.2.10) sobre opinião de Sêneca a respeito de Ênio. 
Enfim, os casos comentados neste estudo permitem avaliar, na técnica de composição dramática de Sêneca, a importância da contaminação de formas discursivas enquanto um fator que fundamenta as características talvez anti-teatrais desses dramas. Esse procedimento de composição, cultivado na poesia helenística e mais provavelmente assimilado por Sêneca através de Ovídio, estaria associado também com prática similar em voga na oratória da época imperial. Considerando-se o conjunto de exemplos apontados, é especialmente notável a tendência de aproximação do drama senequiano ao gênero épico, em função do predomínio de elementos narrativos e descritivos. Embora se trate de uma técnica compositiva que confere ao texto um caráter eminentemente literário, em detrimento da eficácia dramática, no entanto, esta não se perde inteiramente, mas parece concentrar-se em cenas individuais ao longo do poema. ${ }^{49}$

\section{TITLE. Variety of genres and theatricality in the dramas of Seneca}

ABSTRACT. Seneca's dramatic poetry, as in general, the literature of the imperial era is marked by the aesthetic influence of the Hellenistic period. Among other things, the mix of genres, practiced by Alexandrian poets, is largely observable in sanecan dramas, where, however, there are constant references to models not dramatic, especially Horace's lyric and the epic of Virgil and Ovid, in addition to use of formal elements of declamatory speech. Considering the issue discussed at length by critics about the kind of performance that the playwright would have designed for their Latin dramas, then I suggest that the variation of discursive forms, as well as the use of models not dramatic, is a factor that interferes with the theatricality of these plays. The result is a text in which there are some scenes content and features suitable for acting on the stage, along with others, with little effect on scenic and visual, in which stand out rather the auditory effect of the recited text and its descriptive force operating in imagination of the listener.

KEYWORDS. Roman tragedy; Seneca; performance; variety of genres.

${ }^{49}$ Cabe também mencionar uma hipótese formulada por Fitch ('Playing Seneca?', p. 11) de que as peças que figuram entre as primeiras composições (Agamêmnon, Édipo e Fedra), segundo a cronologia relativa estabelecida por ele (J.G. FITCH, Senses-pauses and relative dating in Seneca, Sophocles and Shakespeare, AJPh 102, 289-307, 1981), apresentam reais problemas para a encenação, sendo, portanto, de pouco efeito cênico e de maior efeito literário: assim, em Agamêmnon, o longo relato de Euríbates (421-578) e as cenas do último ato (867ss.); em Fedra, a cena da recomposição do cadáver de Hipólito (1256-80); em Édipo, a cena de sacrifício e extispício (291-402). Já as peças posteriores, especialmente o Tiestes, não ofereceriam maiores entraves à encenação. 